\title{
Trauma urológico
}

\section{Urologic Trauma}

\author{
José Cury', José Luiz Borges de Mesquita², \\ José Pontes ${ }^{3}$, Luiz Carlos Neves de Oliveira ${ }^{3}$, \\ Mauricio Cordeiro ${ }^{4}$, Rafael Ferreira Coelho ${ }^{5}$
}

Cury J, Mesquita JLB de, Pontes J, Oliveira LCN de, Cordeiro M, Coelho RF. Trauma urológico. Rev Med (São Paulo). 2008 jul.-set.;87(3):184-94.

\begin{abstract}
RESUMO: Os traumas geniturinários representam 10\% de todos os traumas em nosso serviço de emergência (HC-FMUSP). O rim é, em geral, o órgão mais freqüentemente envolvido, sendo os traumas de ureter e bexiga mais raros e associados a traumas de alta energia e a outras lesões severas concomitantes. As lesões de ureter são causadas em sua maioria por traumas penetrantes ou por lesões cirúrgicas iatrogênicas. As lesões de uretra, por sua vez, são quase sempre associadas a fraturas do anel pélvico, estando associadas a lesões vesicais em 10 a $17 \%$ dos casos. Um princípio primordial a ser aplicado no diagnóstico do trauma urológico é suspeitar-se da lesão pela avaliação do seu mecanismo e das forças envolvidas no traumatismo, pois os sinais envolvidos são inespecíficos, principalmente em vítimas de trauma fechado. O conhecimento da etiologia, fisiopatologia, diagnóstico e tratamento das principais lesões traumáticas do trato urinário é fundamental para a abordagem adequada do paciente politraumatizado no serviço de emergência. A interação do urologista com o cirurgião do trauma desde os momentos iniciais do atendimento permite guiar as decisões terapêuticas de maneira integrada e congruente. Neste artigo discutiremos os aspectos centrais do diagnóstico e do tratamento das principais lesões do trato geniturinário (TGU).
\end{abstract}

DESCRITORES: Traumatismo múltiplo/complicações. Trato urinário/lesões. Trato urinário/cirurgia. Bexiga urinária. Ferimentos e lesões. Uretra/lesões.

1. Médico Assistente Doutor, Chefe do Grupo de Urogeriatria, Coordenador do Curso de Graduação Médica da Disciplina de Urologia - HC-FMUSP.

2. Médico Assistente Doutor, Chefe do Grupo de Pronto Socorro - HC-FMUSP.

3. Médico Assistente Doutor, HC-FMUSP.

4. Médico Residente em Urologia, HC-FMUSP.

5. Médico Preceptor de Urologia, HC-FMUSP. 


\section{Etiologia e fisiopatologia}

A maioria das lesões renais é causada por traumas fechados (acidentes com veículos automotores, esportes de contato, crimes violentos, quedas), que constituem 82 a $95 \%$ dos traumas renais nos Estados Unidos. Acometem principalmente pacientes jovens, sendo que 70 a $80 \%$ das lesões ocorrem em pacientes com menos de 44 anos. Das lesões renais contusas, $90 \%$ são simples, como a contusão do parênquima renal ou lacerações superficiais que não se estendem para a medula renal ou para o sistema coletor; e 10\% são maiores, estendendo-se até a medula renal ou sistema coletor, promovendo sangramentos mais expressivos e extravasamento de urina para a cavidade abdominal. As lesões de vasos sangüíneos renais associamse a desacelerações rápidas, que podem causar trombose da artéria renal, ruptura da veia renal ou mesmo avulsão de todo o pedículo. As lesões renais causadas por trauma penetrante compreendem os projéteis de arma de fogo e os ferimentos por arma branca que diferem significativamente no tipo e na severidade da lesão $0^{1,2,3}$.

\section{Achados clínicos}

A hematúria é o principal indicador de trauma geniturinário. No entanto, o grau de hematúria não se correlaciona com a severidade das lesões renais. Traumas renais complexos podem não apresentar hematúria, enquanto que hematúria franca pode se observada em contusões renais simples. Fratura da porção inferior do arcabouço costal ou fratura de um processo lombar, hematomas nos flancos e lesão hepática ou esplênica são sinais indiretos de possível trauma renal $\left.\right|^{3,7}$.

\section{Classificação}

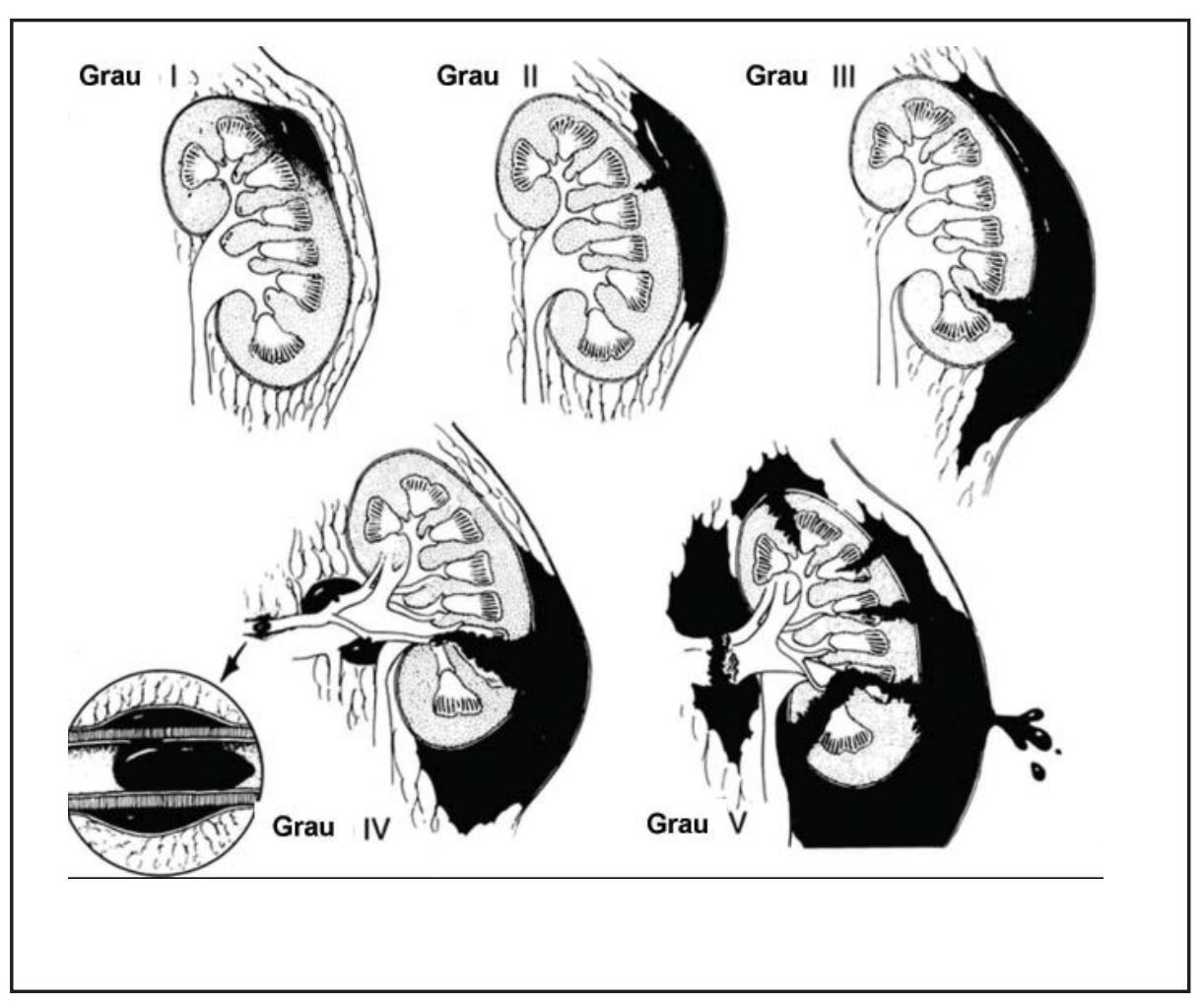

FIGURA 1. Classificação do trauma renal

GRAU I. Contusão ou hematoma subcapsular não expansivo. Sem laceração parenquimatosa.

GRAU II. Hematoma peri-renal não expansivo. Laceração do córtex renal com extensão inferior a $1 \mathrm{~cm}$. Sem extravasamento urinário. GRAU III. Laceração parenquimatosa superior a $1 \mathrm{~cm}$ (estende-se até a medula renal). Sem ruptura do sistema coletor ou extravasamento urinário.

GRAU IV. Laceração atingindo córtex, medula e sistema coletor. Lesão da artéria ou veia renais segmentares, com hemorragia contida. GRAU V. Várias lacerações de grau 4. Rim completamente fragmentado. Avulsão do pedículo com desvascularização renal. 


\section{Exames complementares}

Os quatros principais objetivos dos exames complementares no trauma renal são identificar o grau da lesão, reconhecer patologias pré-existentes, documentar a função do rim contralateral e identificar lesões de outros órgãos associadas. A tomografia computadorizada (TC) com injecção de contraste intravenoso é o exame de escolha na avaliação de lesões renais, mas só pode ser usada em pacientes hemodinamicamente estáveis. Achados na TC que sugerem lesões renais maiores incluem: hematoma medial (sugerindo lesões vasculares), extravasamento urinário (sugerindo lesão de pelve ou avulsão da junção uretero-piélica (JUP), ausência de realce do parênquima por contraste (sugerindo lesão arterial) 2,3,4.

Pacientes instáveis encaminhados à exploração cirúrgica sem avaliação tomográfica podem ser submetidos a uma urografia excretora "one-shot" na sala de operação, administrando-se $2 \mathrm{mg} / \mathrm{kg}$ de contraste endovenoso, dez minutos antes da radiografia de abdome. Se os achados foram anormais o rim pode ser explorado para complementar o estadiamento e reconstruir qualquer lesão encontrada ${ }^{2,3}$.

A arteriografia é largamente utilizada para definir lesões arteriais suspeitas na TC ou localizar sangramentos arteriais que podem ser controlados por embolização como trombose arterial, lesões arteriais segmentares ou pseudoaneurisma ${ }^{6}$.

O ultra-som, em mãos experientes, fornece importantes informações sobre o trauma renal, como a presença dos dois rins e a presença de hematoma retroperitoneal. Entretanto, ele não pode delinear claramente lacerações parenquimatosas, lesões vasculares e lesões do sistema coletor com extravasamento de urina.

\section{Tratamento}

ALGORITMO 1. Trauma renal

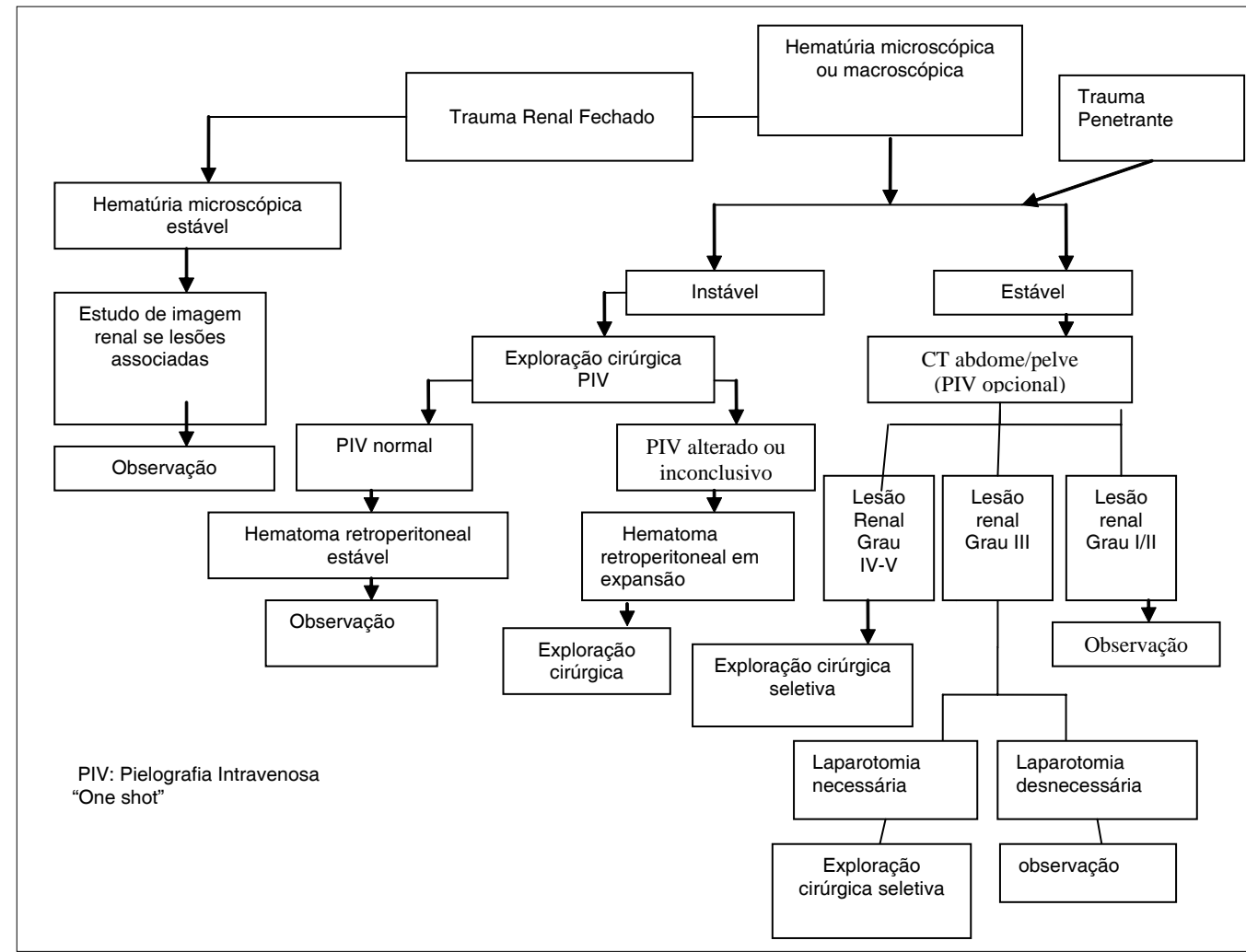

Há poucas indicações absolutas para exploração cirúrgica no trauma renal, sendo que $98 \%$ das lesões renais podem ser tratadas conservadoramente através de internação hospitalar, repouso, seguimento clínico e exames de imagem de controle. Lesões grau IV e V são vistas em apenas 5\% dos traumas renais e necessitam eventualmente de tratamento cirúrgico, mas mesmo tais lesões de alto grau podem ser tratadas conservadoramente se devidamente estagiadas em pacientes selecionados. Traumas penetrantes, contudo, exigem tratamento cirúrgico na maioria dos casos, frente à necessidade 
de exploração da cavidade abdominal para pesquisa de lesões associadas. Ainda assim, existem relatos na literatura de que até $50 \%$ dos ferimentos renais por arma branca e $25 \%$ dos ferimentos por arma de fogo podem também ser tratados conservadoramente $e^{2,7,11}$.

As indicações absolutas para exploração cirúrgica incluem evidência de sangramento renal persistente, avulsão do pedículo renal, hematoma perirrenal pulsátil ou em expansão. Extravasamento urinário, presença de tecido renal não viável, diagnóstico tardio de lesão de artéria renal, lesão de artéria segmentar e impossibilidade de estadiamento completo da lesão são indicações relativas ${ }^{3,7}$. O extravasamento urinário isolado, que não resulta de lesão ureteral ou rotura pélvica não é uma indicação absoluta para exploração cirúrgica podendo se resolver espontaneamente em $76-87 \%$ dos $\operatorname{casos}^{8}$.
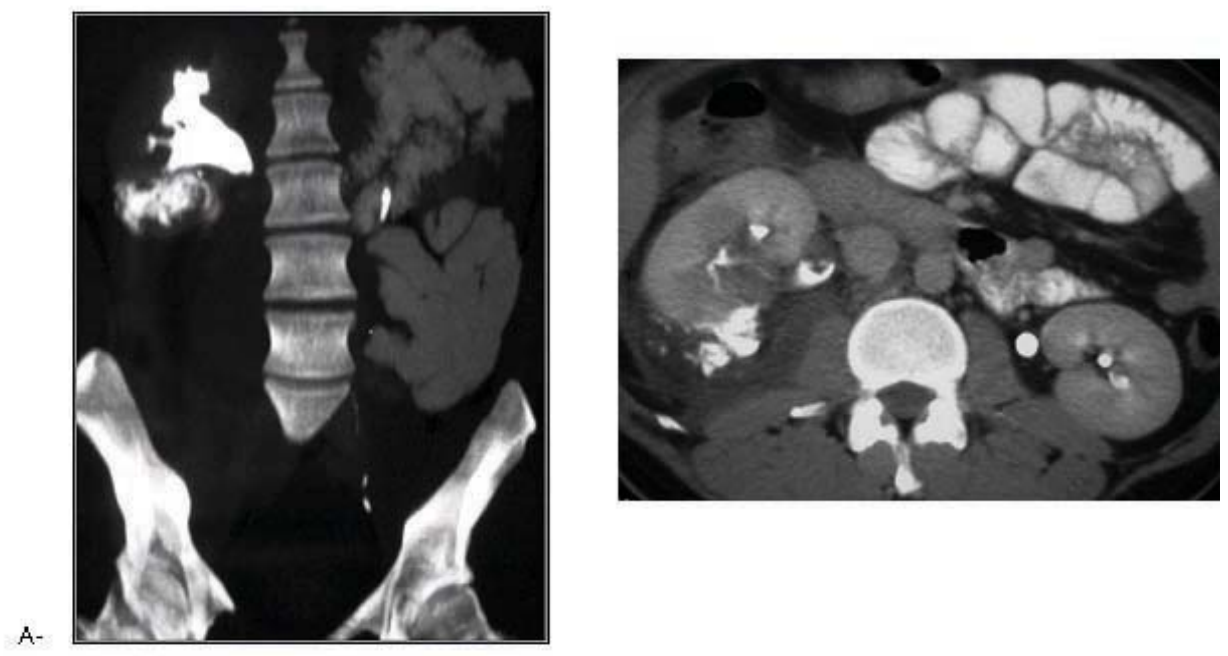

르-

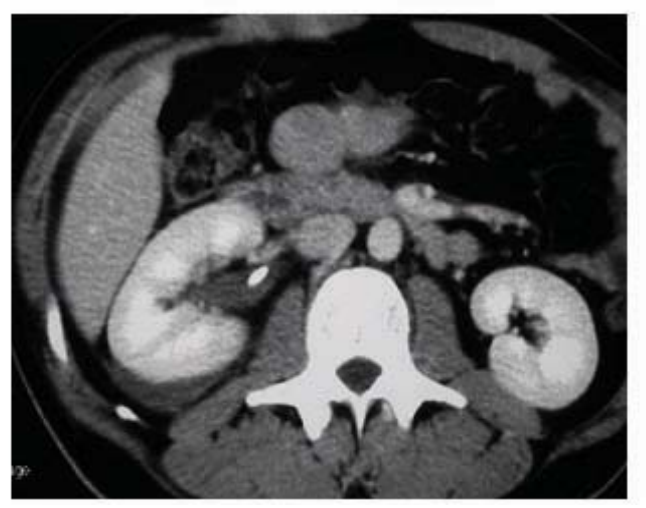

FIGURA 2. A- Trauma renal GIV com extravasamento de contraste pelo sistema coletor e hematoma perirrenal. B- Controle após passagem de cateter duplo J, sem extravasamento de contrataste e com remissão do hematoma perirrenal

Em lesões renais com suspeita de trombose arterial e em lesões arteriais segmentares (lacerações ou pseudoaneurismas) o tratamento minimamente invasivo por meio de arteriografia com a colocação de "stents" ou embolização pode ser considerado. A embolização pode ser usada no sangramento arterial em fase aguda da lesão ou no sangramento tardio. Os sangramentos mais leves podem ser tratados, na maioria das vezes, de maneira conservadora e não causam instabilidade hemodinâmica. Isto ocorre pois a maioria das lacerações renais é radial ou paralela às artérias interlobares. As complicações da embolização são raras. Episódios de hipertensão arterial transitória são comuns, mas hipertensão prolongada ocorre em menos de 1\% dos casos. Quando a área de infarto renal após a embolização é superior a $25 \%$ do 
parênquima total, pode ocorrer febre transitória e leucocitose, que se resolvem espontaneamente, porém, a formação de abscesso ou infecção é incomum 6 .

\section{TRAUMA URETERAL}

\section{Etiologia e fisiopatologia}

A lesão ureteral é causada, geralmente, por trauma penetrante. Lesões viscerais associadas são comuns, acometendo principalmente o intestino delgado (39-65\%), colón (28-33\%) e rim (10-28\%). A mortalidade chega a 33\%. A lesão por trauma fechado é extremamente incomum e ocorre principalmente em crianças com anormalidades congênitas do trato urinário, como hidronefrose secundária à estenose da junção ureteropiélica. Vale lembrar que as lesões ureterais iatrogênicas podem ocorrer após diversos procedimentos cirúrgicos, como a histerectomia (54\%), a cirurgia colorretal (14\%), a cirurgia pélvica de ovário e bexiga ( $8 \%$ ), as cirurgias vasculares abdominais $(6 \%)$ e as ureteroscopias $(2 \%)^{3,7}$.

\section{Achados clínicos}

As manifestações clínicas das lesões ureterais variam com o tipo de lesão e com o tempo decorrido até o seu diagnóstico. Em torno de 25 a $45 \%$ das lesões penetrantes de ureter não apresentam, nem mesmo, hematúria microscópica. Nos casos de obstrução urinária bilateral, secundária à ligadura ou à angulação dos ureteres (trauma iatrogênico), o paciente cursa com anúria no pós-operatório imediato. Quando a obstrução ocorre apenas em um dos lados, situação mais freqüente, o paciente pode apresentar dor na região lombar e no flanco ipsilateral, íleo paralítico, náuseas, vômitos e febre. Nas situações de extravasamento de urina, a manifestação clínica pode ser por peritonite, caso seja intraperitoneal, ou pela formação de tumoração e dor local, se o extravasamento for dirigido para o retroperitônio. Em ambas as situações pode haver febre. A presença de fístula urinária que se exterioriza pela cicatriz cirúrgica ou pela vagina, nos casos de lesão iatrogênica durante procedimento cirúrgico, pode ser a manifestação inicial de uma transecção do ureter. Essas fístulas ureterais se manifestam, geralmente, em torno da segunda semana após o estabelecimento da lesão ${ }^{3,11}$.

\section{Classificação}

Grau I - hematoma: contusão ou hematoma, sem desvascularização.
Grau II - laceração: < 50\% de transecção.

Grau III -laceração: > 50\% de transecção.

Grau IV -laceração: transecção completa com desvascularização $<2 \mathrm{~cm}$.

Grau V -laceração: avulsão com desvascularização $>2 \mathrm{~cm}$.

\section{Exames complementares}

O exame radiológico de eleição para descartar o trauma ureteral é a pielografia retrógrada ou ascendente. Este procedimento permite não apenas diagnosticar a lesão, mas também quantificar sua extensão. Este exame, no entanto, é mais demorado e obriga o posicionamento do paciente em litotomia, fazendo com que a presença de um urologista seja, em geral, necessária para sua realização. A urografia excretora também é um bom exame na avaliação do traumatismo de ureter, embora não tenha a mesma acurácia que a pielografia ascendente.

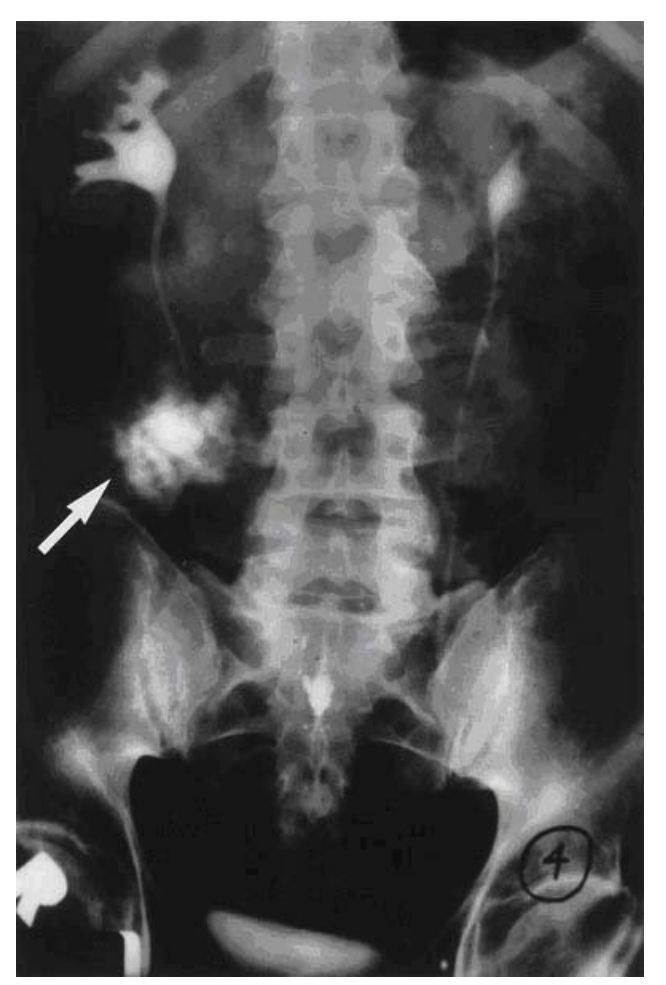

FIGURA 3. Urografia excretora - Lesão ureter proximal/ médio direito com extravasamento de contraste

A tomografia helicoidal também permite a avaliação das lesões ureterais, constituindo o melhor exame para a avaliação do retroperitônio, identificando e quantificando hematomas e coleções. Vale lembrar, no entanto, que é obrigatória a realização de cortes mais tardios para que seja possível a avaliação da 
Cury J, Mesquita JLB de, Pontes J, Oliveira LCN de, Cordeiro M, Coelho RF. Trauma urológico.

via excretoras. Na presença de fístulas, a dosagem de creatinina e de eletrólitos pode diferenciar outras secreções no diagnóstico ${ }^{3,7}$.

\section{Tratamento}

Quando o diagnóstico da lesão ureteral é feito no ato intra-operatório ou no período pós-operatório precoce a correção cirúrgica imediata é a conduta mais adequada. Caso o diagnóstico seja feito tardiamente o tratamento definitivo pode ser postergado. Intervenções durante esse período são dificultadas pela presença de intenso processo inflamatório que pode predispor a lesões ainda maiores do ureter. Nesses casos, o tratamento deve-se restringir ao alívio dos sintomas e preservação do parênquima renal, com derivações urinárias temporárias (por exemplo,nefrostomia percutânea). O tratamento definitivo das lesões ureterais encontra-se diretamente relacionado à sua topografia e extensão. Lesões puntiformes, angulações ureterais e transecções parciais do ureter podem ser conduzidas apenas com cateter ureteral por tempo prolongado (duplo J). Esse procedimento pode ser definitivo para alguns pacientes, enquanto para outros se faz necessária intervenção cirúrgica complementar ${ }^{4,11}$.

As lesões que comprometem o terço superior do ureter podem ser conduzidas com anastomose término-terminal espatulada $(T-T)$ do segmento lesado. As lesões que comprometem o terço médio ureteral, acima da bifurcação dos vasos ilíacos, também apresentam bons resultados com a anastomose T - T. Entretanto, quando o segmento lesado é extenso, a anastomose primária toma-se inviável. Assim, pode-se lançar mão da anastomose lateral do coto proximal do ureter lesado ao ureter contralateral, procedimento conhecido como transuretero-uretero anastomose. Outra forma de conduzir essas lesões é a interposição de um segmento de intestino delgado entre o ureter proximal e a bexiga. $\mathrm{O}$ autotransplante renal, com a translocação do rim para área pélvica, reimplante ureterovesical e anastomose dos vasos renais nos vasos ilíacos, também é uma alternativa para os casos de lesão extensa do ureter. Deve-se lembrar que, nos ferimentos por projéteis de arma de fogo e nas lesões por arma branca, deve ser realizado desbridamento do coto ureteral, para que a anastomose seja feita com boa vascularização e vitalidade dos tecidos. Lesões do ureter pélvico, abaixo da bifurcação dos vasos ilíacos, são mais bem conduzidas com o reimplante ureterovesical. Existem várias técnicas de reimplante, dando-se preferência àquela com a qual o cirurgião esteja mais familiarizado. Nesse procedimento, é fundamental que não haja tensão no local da anastomose. Muitas vezes, quando o segmento ureteral lesado for de maior extensão, faz-se necessária a mobilização e fixação da bexiga ao músculo psoas, técnica conhecida como bexiga psóica ${ }^{4,11}$.

\section{TRAUMA VESICAL}

\section{Etiologia e fisiopatologia}

A lesão de bexiga geralmente resulta de uma agressão à porção inferior do abdômen quando a bexiga está distendida ou da fratura de ossos da bacia. Nesta última o efeito protetor dos ossos pélvicos é perdido durante a fratura e comumente lesões vesicais são causadas por espículas ósseas (causando ruptura vesical extraperitoneal) ou por compressão da cúpula vesical pela presença de urina (causando ruptura intraperitoneal).

\section{Achados clínicos}

Os sinais e sintomas de lesão do trato urinário inferior são frequentemente inespecíficos e incluem incapacidade de urinar (retenção urinária), hematúria macroscópica (95\% dos casos), hematoma escrotal ou perineal, íleo, distensão abdominal e ausência de ruídos hidro-aéreos. Geralmente existe história de traumatismo abdominal, e a maioria dos pacientes refere dor pélvica ou na região inferior do abdômen. $\mathrm{Na}$ sala de emergência, o diagnóstico clínico de fratura pélvica pode ser feito pela compressão lateral da pelve óssea, na qual se nota crepitação e dor. A presença de massa palpável no hipogástrio, associada à hipotensão e à fratura pélvica, geralmente representa um hematoma pélvico. Choque hipovolêmico raramente ocorre em traumatismo vesical puro, estando associado quase sempre a traumatismo de vísceras maciças, fratura pélvica extensa ou lesão de grandes vasos pélvicos ${ }^{3,7}$.

\section{Classificação}

1. Lesões não-penetrantes, contusas ou fechadas:
a) contusão;
b) ruptura extraperitoneal;
c) ruptura intraperitoneal;
d) lesão mista.

2. Lesões penetrantes

\section{Exames complementares}

O exame complementar de escolha para identificar a lesão vesical é a cistografia retrógrada, com 
acurácia de 85 a 100\%. Deve ser realizado em todo paciente com suspeita de trauma vesical. Inicialmente, é realizada uma radiografia simples. A seguir uma solução salina e de contraste, diluída a 30\%, deve ser instilada no interior da bexiga previamente esvaziada através de cateter urinário. Em adultos deve-se usar $400 \mathrm{ml}$ da solução contrastada e, em crianças, o volume infundido deve ser calculado da seguinte forma: $60 \mathrm{ml}+30 \mathrm{ml} /$ ano de idade, até o máximo de 400 $\mathrm{ml}$ de solução de contraste. São realizadas radiografias com grande enchimento vesical e com a bexiga vazia. A realização da radiografia pós-drenagem do contraste é muito importante, uma vez que algumas lesões somente somente são demonstradas com essa radiografia. Apesar da eficácia comprovada da cistografia, a cistotomografia vem suplantando este exame no diagnóstico de lesões vesicais em muitos serviços. Visto que muitos destes pacientes já devem realizar a TC pela presença de hematúria (com possível lesão renal), por fratura pélvica ou por lesão de outros órgãos intra-abdominais, a realização da cistotomografia no mesmo ato do estudo tomográfico abdominal pode poupar tempo. Deve ser realizada a injeção retrógrada de $350 \mathrm{ml}$ de contraste a $30 \%$, diluído a 6:1 com soro fisiológico. Vale lembrar que a injeção de contraste endovenoso e o simples clampeamento da sonda uretral sem injeção do contraste intravesical resulta em um número elevado de exames falso-negativos ${ }^{4,11}$.

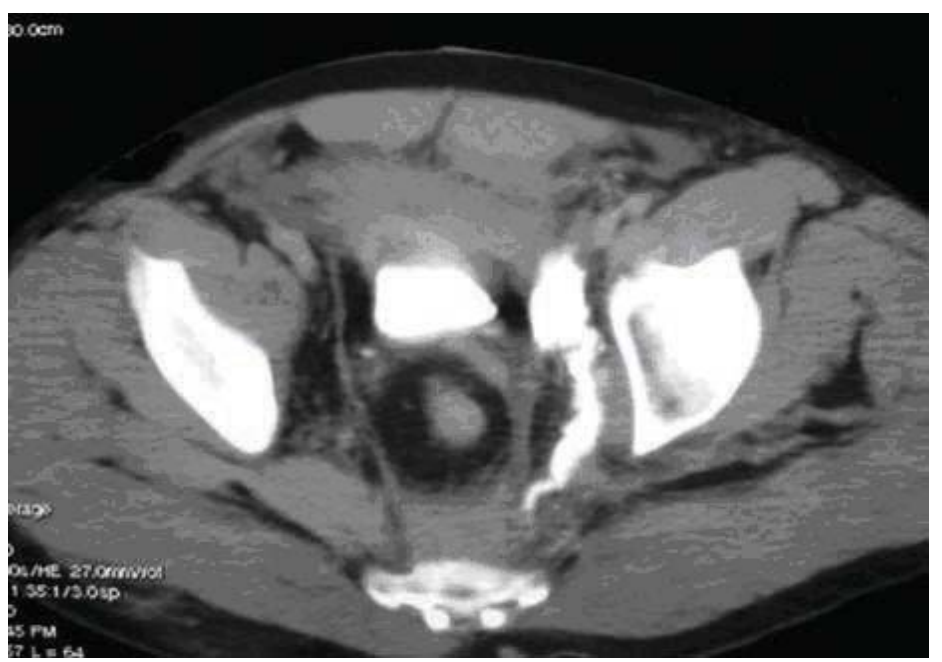

FIGURA 4. Cistotomografia demonstrando rotura intraperitoneal de bexiga (extravasamento de contraste intraperitoneal)

\section{Tratamento}

ALGORITMO 2. Trauma vesical

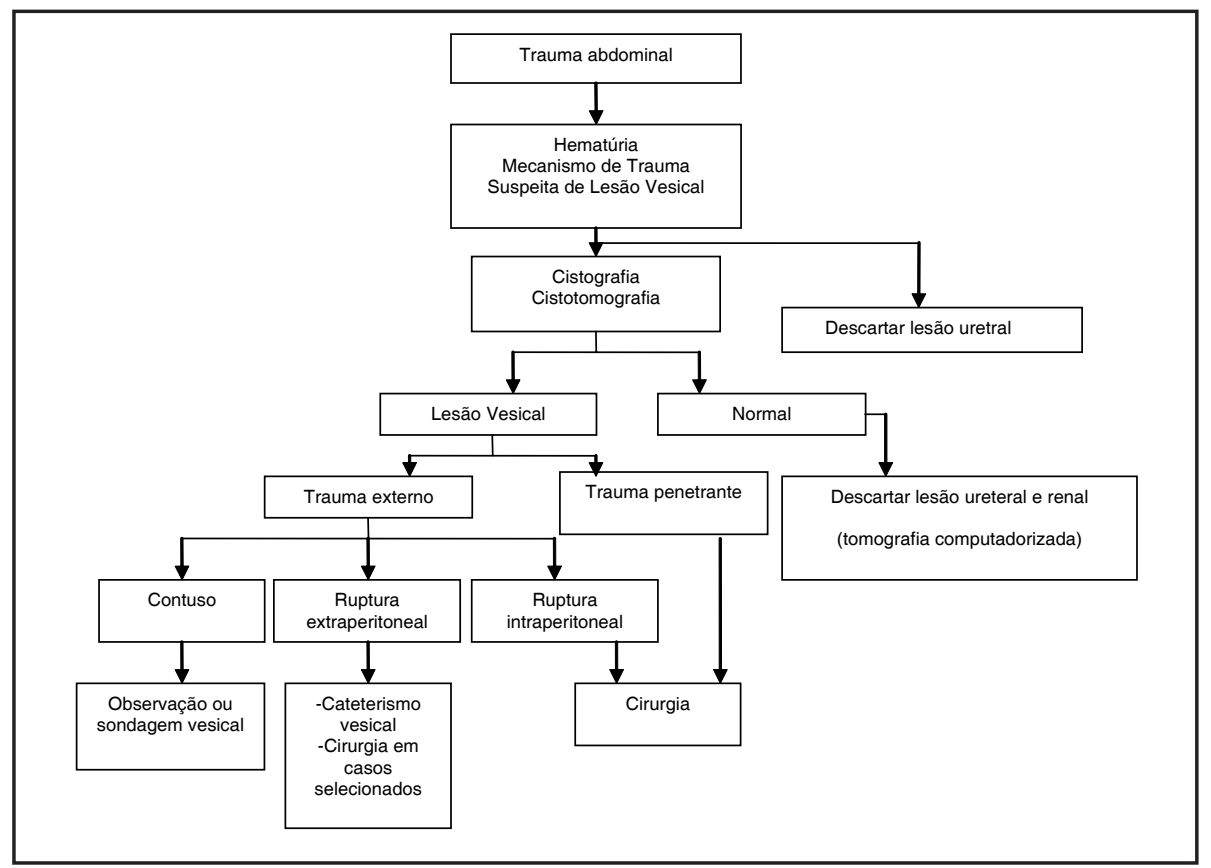


Cury J, Mesquita JLB de, Pontes J, Oliveira LCN de, Cordeiro M, Coelho RF. Trauma urológico.

\section{Contusão}

Quando a contusão vesical for leve e o paciente apresentar apenas micro-hematúria, não há necessidade de qualquer tratamento, bastando orientar o paciente para que se mantenha bem hidratado. Contusão vesical com hematúria intensa é tratada por meio de drenagem com sonda de Foley de três vias e irrigação vesical contínua. Geralmente, com esse tipo de tratamento, a bexiga retoma a sua condição normal em poucos dias. Enquanto o paciente permanecer sondado, o uso de antibióticos se faz necessário ${ }^{3,4,5}$.

\section{Ruptura extraperitoneal}

O tratamento clássico utilizado para a lesão extraperitoneal de bexiga é o tratamento conservador através de sondagem vesical de demora por 10 dias, associada ao uso de antibióticos. Com esse tratamento, cerca de $85 \%$ das lesões vesicais estão cicatrizadas no momento da retirada da sonda de Foley. O tratamento cirúrgico fica reservado para casos especiais como, por exemplo, lesões vesicais associadas à presença de fragmentos ósseos intravesicais, fraturas pélvicas expostas, perfuração de reto ou quando o paciente for submetido a qualquer outro procedimento cirúrgico, desde que não se encontre instável hemodinamicamente. A exploração cirúrgica da ruptura extraperitoneal é realizada mediante uma incisão supra-púbica longitudinal. A síntese vesical é realizada por meio de sutura contínua com fio absorvível em dois planos de sutura. Cistostomia supra-púbica pode ser utilizada. Caso se encontre hematoma pélvico durante a cirurgia, não é conveniente a exploração dessa região. A retirada da sonda de Foley deve ser feita somente após a realização de cistografia de controle que não demonstre extravasamento de contraste $e^{3,4,5}$.

\section{Ruptura intraperitoneal}

O tratamento clássico para a ruptura intraperitoneal de bexiga é o tratamento cirúrgico. Geralmente a lesão vesical encontra-se na cúpula por ser esta a região mais frágil do órgão. Se necessário, deve-se ampliar a própria lesão para que se tenha acesso a todas as paredes da bexiga. Qualquer lesão extraperitoneal concomitante deve, então, ser corrigida. Em seguida, pode ser realizada cistostomia supra-púbica extraperitoneal, e o espaço pré-vesical, drenado. É conveniente a utilização de antibióticos. O controle radiológico por meio de cistografia deve ser realizado no $10^{\circ}$ dia pós-operatório e, caso não se evidencie extravasamento, a sonda de Foley é retirada ${ }^{3,4,5}$.

\section{TRAUMA URETRAL}

\section{Etiologia e fisiopatologia}

A lesão de uretra é muito mais comum em homens, ocorrendo em mulheres em menos de $2 \%$ dos casos. As lesões de uretra podem ser divididas em dois níveis: uretra posterior (prostática e membranosa) e anterior (bulbar e peniana). A uretra bulbar é o segmento da uretra anterior mais comumente acometido e sua lesão associa-se, em geral, aos traumas diretos do períneo, com compressão deste seguimento uretral contra a pelve (o chamado "trauma a cavaleiro"). Já a lesão de uretra posterior, de forma semelhante à lesão de bexiga, está associada à fratura de pelve, em que a disjunção osteoligamentar ou as espículas ósseas promovem secção uretral ${ }^{3,7}$.

\section{Achados clínicos}

As lesões da uretra posterior se manifestam com dor hipogástrica e dificuldade ou incapacidade de urinar. A presença de sangue no meato uretral é o sinal mais importante de lesão de uretra. A presença de fratura pélvica também pode ser identificada no exame físico. Um grande hematoma pélvico em formação pode muitas vezes ser palpado e contusões perineais ou supra-púbicas também estão presentes. O toque retal pode revelar um hematoma pélvico com a próstata deslocada superiormente. $O$ deslocamento superior não é observado se os ligamentos puboprostáticos e o diafragma urogenital permanecem íntegros.

No caso das lesões de uretra anterior, existe, em geral, uma historia de queda ou instrumentação uretral. Os pacientes se queixam de dor perineal e um hematoma perineal em asa de borboleta em geral está presente. Com o extravasamento de urina também pode ocorrer edema súbito do períneo. 0 hematoma pode ficar restrito à haste do pênis quando a fáscia de Buck esta íntegra. Quando esta se rompe o hematoma é contido pela fáscia de Colles, estendendo-se para o escroto, o períneo e até para a parede abdominal ${ }^{3,7}$.

\section{Classificação}

- Tipo I: Alongamento e distração uretral causados pelo hematoma pélvico, sem ruptura.

- Tipo II: Ruptura parcial ou completa da uretra, extravasamento de contraste confinado abaixo do 
diafragma urogenital.

- Tipo III: Ruptura completa da uretra posterior e do diafragma urogenital, extravasamento de contraste proximal e distal ao diafragma urogenital. São as mais freqüentes.

\section{Exames complementares}

Os pacientes com suspeita de ruptura de uretra devem ser submetidos à uretrografia retrógrada. Existem diversos métodos descritos para realização deste exame diagnóstico. Em nosso serviço utilizamos uma sonda de foley $14 \mathrm{Fr}$, introduzida por 1 a 2 $\mathrm{cm}$ na fossa navicular e insuflamos o balão de 1 a 2 $\mathrm{ml}$. Utilizamos contraste iodado a $30 \%$ e o injetamos lentamente na uretra, em frações de 10 ml. Radiografias estáticas em decúbito lateral são aceitáveis, mas a realização do exame sob visão fluoroscópica fornece mais informações. Extravasamento de contraste com ausência de delineação da uretra proximal e bexiga indica ruptura completa de uretra, enquanto o extravasamento com chegada de contraste até a bexiga traduz lesão parcial ${ }^{4,11}$.

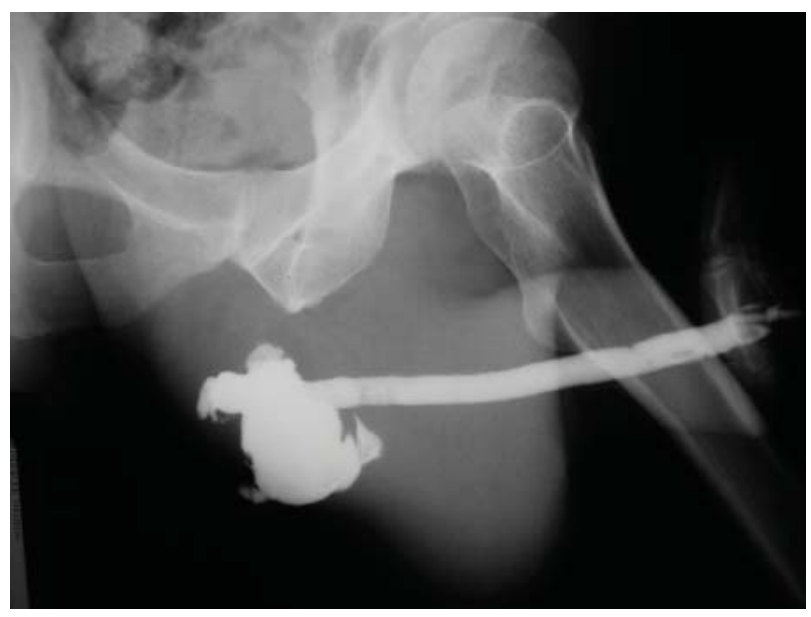

FIGURA 5. Lesão completa de uretra bulbar após queda a cavaleiro

\section{Tratamento}

\section{ALGORITMO 3. Trauma de uretra}

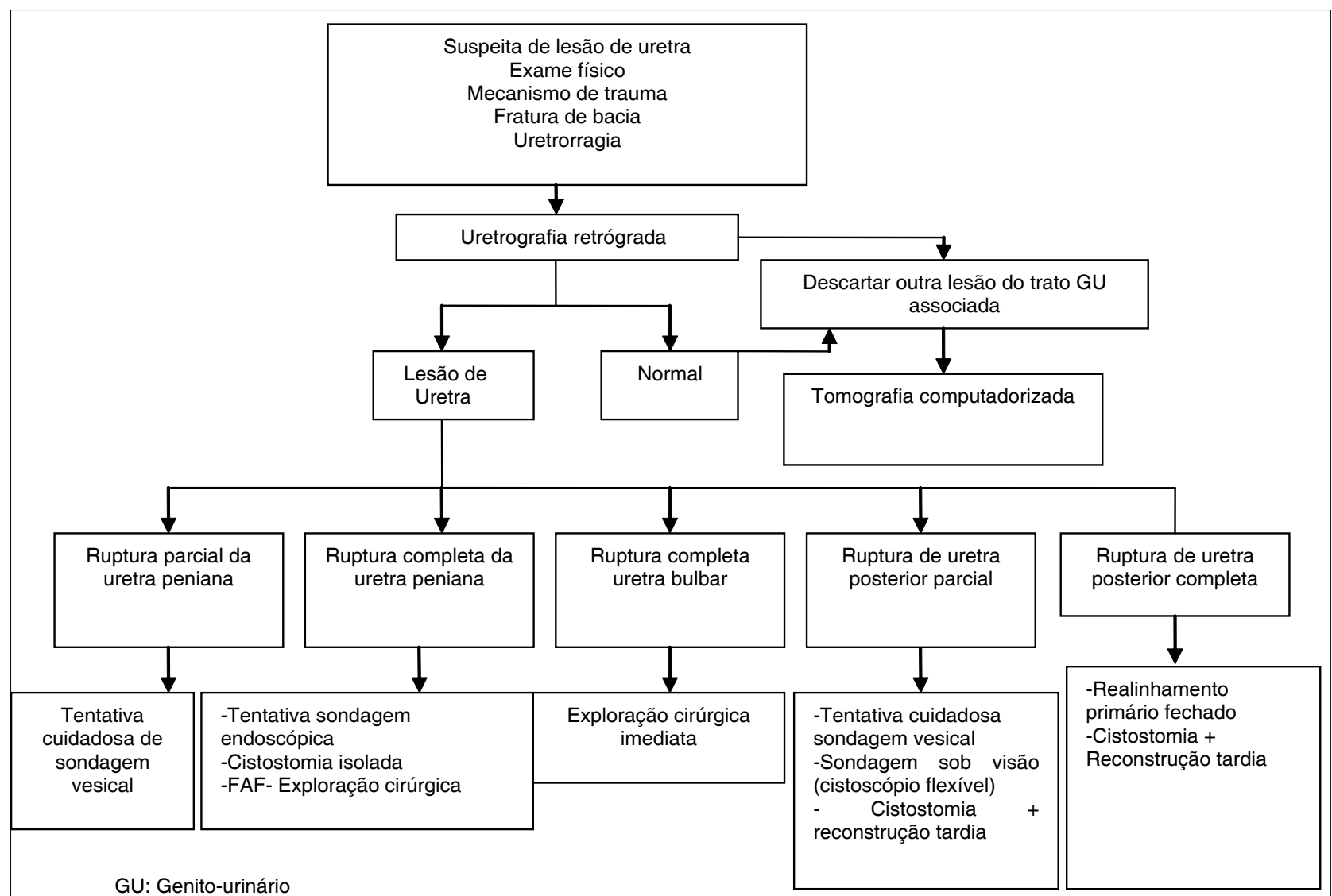


Cury J, Mesquita JLB de, Pontes J, Oliveira LCN de, Cordeiro M, Coelho RF. Trauma urológico.

- Ruptura da uretra peniana - Tentativa cuidadosa de passagem de sonda uretral Foley, seguida de estudo radiológico para confirmar o posicionamento correto da sonda na bexiga. A sonda é mantida por 14 dias. Nos casos de insucesso da tentativa inicial de sondagem, pode-se tentar a sondagem por via endoscópica ou mesmo realizar cistostomia, que é mantida até o desaparecimento do extravasamento local. Lesões causadas por armas de fogo podem ser exploradas cirurgicamente. A exploração cirúrgica nas lesões mais proximais é feita por acesso perineal, enquanto nas lesões distais utilizamos a circuncisão e o desenluvamento peniano $2,3,4,9,11$.

- Ruptura de uretra bulbar - Tratamento controverso. Em rupturas parciais, o cateterismo vesical por 7 a 14 dias tem altos índices de sucesso. Na maioria das lesões completas há inclinação à exploração cirúrgica imediata. Alguns autores advogam, entretanto, realização de cistostomia em todos os casos. Nos casos de ruptura completa defendemos, em nosso serviço, a exploração cirúrgica imediata. A lesão é acessada através de uma perineotomia, é feita a anastomose dos cotos uretrais sobre uma sonda de foley que é deixada por, no mínimo, 14 dias. Em ferimentos por arma de fogo, a cistostomia supra-púbica e a reconstrução tardia entre 6 semanas e 3 meses podem ser adotados $23,4,9,11$.

- Ruptura da uretra posterior - Em lesões de uretra posterior do tipo I, ou seja, em que há apenas estiramento da uretra, sem ruptura, o tratamento deve ser cateterismo vesical por 5 dias. Nos casos de ruptura parcial ou completa da uretra posterior o tratamento é controverso. Em rupturas parciais pode ser tentada uma sondagem cuidadosa, feita por um urologista experiente. Alguns autores alegam, entretanto, que tal manobra pode converte uma transecção incompleta em completa. A opção, nestes casos, seria, então, a tentativa de sondagem, com auxilio de um cistoscópio flexível. Nas rupturas completas, a abordagem inclui o realinhamento fechado pelo cateterismo uretral combinado, o realinhamento cirúrgico imediato e a realização de uma cistostomia supra-púbica com reconstrução tardia da uretra.

A conduta clássica e mais simples é a realização de cistostomia supra-púbica isolada, sem manipulação da área traumatizada. A justificativa para tal conduta é a de que a manipulação imediata da bexiga e da próstata aumenta os riscos de impotência sexual e incontinência urinária e dificulta a reconstrução posterior nos casos de insucesso do tratamento inicial. Outra conduta que tem ganhado espaço e que se tornou o tratamento padrão inicial para o trauma de uretra posterior em muitos serviços é o realinhamento fechado pelo cateterismo uretral combinado. O cateterismo combinado, anterógrado e retrógrado, auxilia na cicatrização local, podendo evitar o desenvolvimento posterior de estenose, complicação inevitável quando realizamos apenas cistostomia. São várias as técnicas empregadas no realinhamento fechado, incluindo: realização de uma cistotomia aberta com passagem de um cateter uretral (guiado digitalmente em direção à bexiga através da palpação direta da parede anterior da próstata); realização de uma cistoscopia flexível anterógrada como guia para passagem retrógrada do cateter uretral; ou mesmo a passagem de fio guia por cistoscopia flexível ou a passagem anterógrada de um cateter como guia para a sondagem retrógrada. A sonda uretral deve permanece por 4 a 6 semanas após a sondagem ${ }^{2,3,4,9,11}$.

Cury J, Mesquita JLB de, Pontes J, Oliveira LCN de, Cordeiro M, Coelho RF. Urologic Trauma. Rev Med (São Paulo). 2008 jul.-set.;87(3):184-94.

\begin{abstract}
The genitourinary trauma represents $10 \%$ of all traumas in our Emergency Service (HC-FMUSP). The kidney is the organ most frequently affected. The ureteral and bladder traumas are rarer and are associated with traumas of high energy and with other severe injuries. The ureteral injuries are, mostly, caused by penetrating traumas or by surgical and iatrogenic injuries. The urethral injuries, otherwise, are associated with pelvis fracture in almost all cases and with bladder injury in 10 to $17 \%$ of the cases. An essential principle to be applied on diagnosis of urologic injuries is the evaluation of the mechanisms and the energy involved in the trauma, especially in victims of blunt injuries. Knowing the etiology, physiopathology, diagnosis and treatment of the genitourinary trauma is essential for the correct approach of the polytraumatized patient at the Emergency Service. The interaction between the Urologist and the Trauma Surgeon since the earlier moments at the emergency room can help to guide the therapeutic decisions on an integrated and congruent way. In this article we will discuss the main aspects of diagnosis and treatment of genitourinary tract trauma.
\end{abstract}

KEY WORDS: Multiple trauma/complications. Urinary tract/injuries. Urinary bladder. Urethra injuries. Wounds and injuries. 


\section{REFERÊNCIAS}

1. Baverstock R, Simons R, Mc Loughlin Severe blunt renal trauma: a 7-year retrospective review from a provincial trauma centre. Can J Urol. 2001;8:1372-6.

2. Bendhack DA, Damião R. Guia prático de urologia. Rio de Janeiro: Sociedade Brasileira de Urologia; 1999.

3. Cury J, Coelho RF, Saito F. Trauma geniturinário. In: Martins HS, Damasceno MCT, Awada SB. Pronto Socorro: condutas do Hospital das Clínicas da Faculdade de Medicina da Universidade de São Paulo. 2a ed. São Paulo: Manole; 2008.

4. Cury J, Simonetti R, Srougi M. Urgências em urologia. São Paulo: Sarvier; 1999.

5. Gomez RG, Ceballos L, Coburn M, Corriere JM Jr, Dixon CM, Label B, et al. Consensus statement on bladder injuries. BJU Int. 2004;94(1):27-32.

6. Kitase M, Mizutani M, Tomita H, Kono T, Sugie C, Shibamoto $\mathrm{Y}$. Blunt renal trauma: comparison of contrast-enhanced CT and angiographic findings and the usefulness of transcatheter arterial embolization. Vasa. 2007;36:108-13.

7. Lynch TH, Martínez-Piñeiro L, Plas E, Serafetinides E, Türkeri L, Santucci RA, et al. European Association of Urology. EAU guidelines on urological trauma. Eur Urol. 2005;47(1):1-15.

8. Mattews LA, Smith EM, Spinark JP. Nonoperative treatment of major blunt renal lacerations with urinary extravasation. J Urol. 1997;157:2056-8.

9. Morey AF. Consensus statement on urethral trauma. J Urol. 2005;174(3):968-9.

10. Santucci RA, Wessells H, Bartsch G, Descotes J, Heyns $\mathrm{CF}$, McAninch JW, et al. Evaluation and management of renal injuries: consensus statement of the renal trauma subcommittee. BJU Int. 2004;93(7):937-54.

11. Wein AJ,Kavoussi AC, Partin AW, Peters CA. CampbellWalsh urology. 9th ed. Philadelphia: WB Saunders; 2007. 